\title{
Body Mass Index Is Associated with Dietary Patterns and Health Conditions in Georgia Centenarians
}

\author{
Dorothy B. Hausman, ${ }^{1}$ Mary Ann Johnson, ${ }^{1}$ Adam Davey, ${ }^{2}$ and Leonard W. Poon ${ }^{3}$ \\ ${ }^{1}$ Department of Foods and Nutrition, University of Georgia, 280 Dawson Hall, Athens, GA 30602, USA \\ ${ }^{2}$ Department of Public Health, Temple University, Philadelphia, PA 19122, USA \\ ${ }^{3}$ Institute of Gerontology, University of Georgia, Athens, GA 30602, USA
}

Correspondence should be addressed to Dorothy B. Hausman, dhausman@uga.edu

Received 2 March 2011; Accepted 4 April 2011

Academic Editor: Bo A. Hagberg

Copyright (c) 2011 Dorothy B. Hausman et al. This is an open access article distributed under the Creative Commons Attribution License, which permits unrestricted use, distribution, and reproduction in any medium, provided the original work is properly cited.

\begin{abstract}
Associations between body mass index (BMI) and dietary patterns and health conditions were explored in a population-based multiethnic sample of centenarians from northern Georgia. BMI $\leq 20$ and $\geq 25$ was prevalent in $30.9 \%$ and $25.3 \%$ of study participants, respectively. In a series of logistic regression analyses controlled for gender and place of residence, the probability of having BMI $\geq 25$ was increased by being black versus white and having a low citrus fruit, noncitrus fruit, orange/yellow vegetable or total fruit and vegetable intake. The probability of having BMI $\leq 20$ was not associated with dietary intake. When controlled for race, gender, residence, and total fruit and vegetable intake, BMI $\geq 25$ was an independent risk factor for diabetes or having a systolic blood pressure $\geq 140 \mathrm{mmHg}$ or diastolic blood pressure $\geq 90 \mathrm{mmHg}$, whereas BMI $\leq 20$ was a risk factor for anemia. Given the many potential adverse consequences of under- and overweight, efforts are needed to maintain a healthy weight, even in the oldest old.
\end{abstract}

\section{Introduction}

Body mass index is a simple index of weight for height that is frequently used in the assessment of nutritional status. A low BMI, or underweight status, is often associated with an increased risk of mortality in seriously ill or hospitalized older adults $[1,2]$. Conversely, a high BMI, indicative of overweight or obesity, is associated with an exacerbation in age-related physical and cognitive decline $[3,4]$ and with an increased prevalence or risk of many chronic health conditions common in older adults such as diabetes, hypertension, and cardiovascular disease [3-5]. Such associations are typically determined across the entire spectrum of older adults (aged 60+), with no further demarcation within this age classification. Our finding of a much higher prevalence of several nutritional deficiencies in centenarians as compared with octogenarians $[6,7]$, suggests that there is considerable heterogeneity in nutrient status in the "older adult" age group. Likewise, there may also be considerable heterogeneity within the older adult age group with regard to chronic health conditions. Thus, it is not known whether the associations between underweight or overweight/obesity and chronic health conditions as observed in previous studies of older adults extend to the very old.

Dietary intake patterns featuring a high intake of nutrient-dense foods such as cereals, fruits, vegetables, and low-fat meat and dairy products have been associated with a number of favorable health outcomes in adults including a decreased prevalence of obesity $[8,9]$, lower rates of weight gain over time [10], and better quality of life and improved survival [11]. In contrast, low-nutrient dense dietary patterns with high intakes of sweets, desserts, and high-fat dairy products have been associated with higher rates of obesity and poor nutritional status in older adults [9]. Whether these observations extend to the very old is unknown. Studies comparing energy intakes and dietary intake patterns of centenarians to younger older adult cohorts have generally observed lower energy and/or fat intake in the centenarians, while dietary preferences of centenarians are considerably more varied and dependent of the region of study likely reflecting cultural patterns and cohort differences rather than longevity-related differences 
per se (reviewed [12]). Nonetheless, there can be considerable variation of body weight status within a given group of centenarians [13], though to our knowledge the extent to which this may be associated with potential differences in dietary intake patterns or selected health conditions has not been explored. Thus, the objectives of this study were to explore associations (1) between BMI and dietary habits and (2) between underweight or overweight/obesity and health status in a population-based multiethnic sample of centenarians (98 years and above) from northern Georgia in the USA. It was hypothesized that overweight/obesity, but not underweight, would be associated with poorer dietary habits and that both overweight/obesity and underweight, as well as dietary habits, would be associated with specific health conditions in this population.

\section{Methods}

2.1. Study Population. This study was a secondary analysis of data collected by the Georgia Centenarian Study, a population-based multidisciplinary study conducted in 44 counties in northern Georgia (USA) from 2002 to 2005. The original study included 244 centenarians (defined as age 98 and older). The sampling procedures and data collection methods have been described elsewhere [6, 14]. Briefly, recruitment of participants from skilled nursing facilities was based on estimates of the institutionalized population of the area according to the 2000 US Census tabulations. The community dwelling participants resided in private residences and personal care homes and were recruited from voter registration lists. Participants were recruited to match census figures for gender and race/ethnicity (white or black; all were non-Hispanic) and were interviewed by trained personnel in their place of residence. All questionnaires and procedures were approved by the University of Georgia Institutional Review Board on Human Subjects.

2.2. Demographic, Nutrition, and Health Information. Information regarding age, gender, race/ethnicity, living arrangements, health conditions (cardiovascular disease, diabetes, hypertension, etc.), and behaviors (including tobacco and nutritional supplement use) were obtained from each participant (or his/her caregiver) by self-report. Questions regarding food intake, appetite, and weight change were adapted from the Mini-Nutritional Assessment [15, 16] and the response categories for food intake represented current frequency of consumption of food groups, including dairy products (milk, yogurt, and cheese); meat, fish, or poultry; orange/yellow vegetables; green vegetables; citrus and noncitrus fruit and juice. The total food score, ranging from 0 to 5 , was based on comparisons with the Dietary Guidelines for Americans [17] 1,600-calorie meal pattern for sedentary older adults, as previously described [16].

Body weight and height were measured by interviewers, obtained from charts or via self-report. In addition, knee height was measured on the right leg, unless contraindicated, to the nearest 0.1 centimeter and used to predict stature as per the formulas of Chumlea et al. [18]. Body mass index (BMI) was calculated as weight $(\mathrm{kg}) /$ height (meters) $)^{2}$.
BMI calculated from observed/recorded height and weight was highly correlated with BMI calculated from predicted stature [18] and observed/recorded weight $(r=0.877$; $P<.0001)$. BMI calculated from observed/recorded height and weight was used to form three BMI classifications based on the National Institutes of Health criteria [19] for overweight/obesity and defined as underweight $\leq 20 \mathrm{~kg} / \mathrm{m}^{2}$, normal weight $>20$ and $<25 \mathrm{~kg} / \mathrm{m}^{2}$, and overweight/obese $\geq 25 \mathrm{~kg} / \mathrm{m}^{2}$. Triceps skinfold (TSF) was measured on the right arm, unless contraindicated, by caliper to the nearest 0.1 millimeter. Mid-arm circumference (MAC) was measured on the right arm, unless contraindicated, to the nearest 0.1 centimeter. Systolic and diastolic blood pressure measurements were obtained with a brachial cuff.

2.3. Biochemical Indices. Nonfasting blood samples were collected as previously described $[6,14]$. Hemoglobin was assessed by a clinical diagnostic laboratory (LabCorp, Inc., Burlington, NC) and anemia was defined as hemoglobin $<12 \mathrm{~g} / \mathrm{dL}$ for females or $<13 \mathrm{~g} / \mathrm{dL}$ for males [20].

2.4. Exclusions from Data Analysis. Participants missing data for primary variables of interest were excluded from the present analyses. From the original sample of centenarians, 11 individuals were excluded due to missing data for BMI ( $n=7$; includes one double-amputee), food intake patterns $(n=1)$, average grip strength $(n=1)$, and/or systolic/diastolic blood pressure $(n=3)$. Overall characteristics of the 233 centenarians included in the study are given in Table 1. Compared to the included centenarians $(n=233)$, the excluded centenarians tended to be older $(102.6 \pm 3.6$ versus $100.5 \pm 1.9$ yrs; $P=.052)$, but did not differ in gender $(90.9 \%$ [excluded] versus $84.6 \%$ female), race/ethnicity $(72.7 \%$ versus $79.0 \%$ white $)$, or place of residence (36.4\% versus $43.4 \%$ skilled nursing facility).

2.5. Statistical Analyses. Means, standard deviations, medians, range of values, and/or frequencies were calculated. Differences between participants with different BMI classifications were assessed with the Wilcoxon rank sum test for continuous variables and Chi square analysis for categorical variables. Probabilities reported are unadjusted for multiple tests. The level of significance was set at $P<.05$.

Because the food groups provide calories, a series of logistic regression analyses were performed with BMI $\leq 20$ or $\mathrm{BMI} \geq 25$ as the dependent variable and gender, race/ethnicity, living arrangements, and reported intake of specific food groups as the independent variables. In addition, because BMI can play a causative role as a risk factor for chronic disease, a second series of logistic regression analyses was performed with diabetes, anemia, or other chronic health conditions as the dependent variable and race, gender, residence, and $\mathrm{BMI} \leq 20$ or $\mathrm{BMI}>25$ as the independent variables (Model 1). A final series of logistic regression analyses was performed with diabetes, anemia, or other chronic health conditions as the dependent variable and race, gender, residence, total fruit, and vegetable intake and BMI $\leq 20$ or BMI $>25$ as the independent variables (Model 2). 
TABLE 1: Characteristics of study participants.

\begin{tabular}{|c|c|}
\hline & $\begin{array}{c}\text { Mean } \pm \text { SD, or } \% \\
(\text { minimum }- \text { maximum })\end{array}$ \\
\hline Age (y) & $100.5 \pm 1.9(98-108)$ \\
\hline \multicolumn{2}{|l|}{ Gender } \\
\hline Women $(\%)$ & 84.6 \\
\hline Men (\%) & 15.4 \\
\hline \multicolumn{2}{|l|}{ Race } \\
\hline White (\%) & 79.0 \\
\hline African American (\%) & 21.0 \\
\hline \multicolumn{2}{|l|}{ Living arrangements } \\
\hline Skilled nursing facility (\%) & 43.4 \\
\hline Community (\%) & 56.6 \\
\hline Total food score ${ }^{1}$ & $3.1 \pm 1.6(0-5)$ \\
\hline $\operatorname{BMI}\left(\mathrm{kg} / \mathrm{m}^{2}\right)$ & $22.5 \pm 4.2(14.0-35.2)$ \\
\hline Mid-arm circumference & $23.8 \pm 4.3(7.5-37.1)$ \\
\hline Triceps skin fold & $11.1 \pm 5.7(2.8-34.0)$ \\
\hline \multicolumn{2}{|l|}{ Blood pressure ( $\mathrm{mm} \mathrm{Hg}$ ) } \\
\hline Systolic & $127.7 \pm 15.1(90-190)$ \\
\hline Diastolic & $73.8 \pm 9.4(38-100)$ \\
\hline Hemoglobin $(\mathrm{g} / \mathrm{dL})$ & $12.0 \pm 1.5(7.5-16.7)$ \\
\hline \multicolumn{2}{|c|}{$\begin{array}{l}{ }^{1} \text { Total food score ranged from } 0 \text { to } 5 \text { and one point was given for meeting } \\
\text { each recommended serving from five food groups as follows: two or more } \\
\text { servings of meat, poultry, or fish daily, two or more servings of dairy foods } \\
\text { daily, four or more servings of green vegetables weekly, three or more } \\
\text { servings of orange or yellow vegetables weekly, and three or more servings } \\
\text { of fruit daily [16]. }\end{array}$} \\
\hline
\end{tabular}

$P$-values are unadjusted for multiple comparisons, because all comparisons were preplanned. Analyses were conducted using SAS 9.2 (SAS, Cary, NC).

\section{Results}

Approximately one-third (31.3\%) of the centenarians included in the final analytical sample had a BMI of $\leq 20$ (underweight), 43.8\% were classified as being in the normal weight range, and $24.9 \%$ met the NIH classification for overweight/obesity (BMI $\geq 25$ ). Triceps skin fold (TSF) and mid-arm circumference (MAC) of centenarians in the lowest BMI classification averaged below the 5 th percentile for females $80+$ years in USA based on 2003-2006 NHANES data [21]. Both parameters increased with BMI classification in a stepwise manner (data not shown) and were highly correlated with BMI (Pearson Correlation Coefficient between $\mathrm{BMI}$ and $\mathrm{TSF}=0.482$; and between $\mathrm{BMI}$ and $\mathrm{MAC}=0.624$; $P<.0001$ for both).

Chi-square analysis indicated that those with a BMI $\leq 20$ were more likely to be women, live in a skilled nursing facility, eat a modified food diet, have experienced a weight change in the past three months, and have anemia as compared to centenarians classified as normal weight or overweight/obese (Table 2 ). Conversely, those with a BMI $\geq 25$ were more likely to be black, diabetic, have a higher systolic blood pressure, and/or have a diastolic blood pressure $\geq 90 \mathrm{~mm}$ as compared to centenarians classified as underweight or normal weight. There were no differences according to BMI classification with regard to history of CVD, cancer, stroke, depression, or past or current tobacco use.

Bivariate analysis of diet intake patterns suggested that centenarians with $\mathrm{BMI} \leq 20$ had the highest total food scores and were more likely to report eating two or more servings of meat, fish, and poultry per day and three or more total servings of fruit per day as compared with centenarians in the other BMI classifications. In contrast, those with a BMI $\geq 25$ were more likely to report eating less than one serving of citrus or noncitrus fruit per day, less than four servings of orange/yellow vegetables per week, or three total servings of fruit and vegetables per day (Table 2). A series of logistic regression analyses indicated that when controlled for gender, race, and place of residence the odds of having a $\mathrm{BMI} \geq 25$ were about two to three times higher in centenarians with lower intakes of citrus and noncitrus fruit (less than one serving per day), orange and yellow vegetables (less than four servings per week), or total fruits and vegetables (less than three servings per day), but were not related to intake of the meat group or dairy group (Table 3 ). Similar analyses with BMI $\leq 20$ as the dependent variable, failed to show any significant association with dietary intake categories (Table 3).

Finally, associations between BMI classifications and chronic health conditions were determined in a series of logistic regression analyses that included either BMI $\leq 20$ or $\mathrm{BMI} \geq 25$ as an independent variable (Table 4 ). When controlled for gender, race, and place of residence, the odds of having anemia, based on blood hemoglobin values, were over twofold higher in centenarians with BMI $\leq 20$ versus those with BMI $>20$ whereas the odds of self-reported CVD tended to be reduced in those in the underweight classification ( $\mathrm{BMI} \leq 20 ; P=.053)$. The latter finding became significant in regression models further controlled for total fruit and vegetable intake (Model 2; $P=.048$ ). In analyses controlled for gender, race, and place of residence, the odds of having self-reported diabetes or systolic blood pressure $\geq 140 \mathrm{mmHg}$ were approximately three- and twofold higher, respectively, in centenarians with $\mathrm{BMI} \geq 25$ versus those with BMI $<25$. Being overweight/obese $(\mathrm{BMI} \geq 25)$ also tended to increase the odds of having diastolic blood pressure $>90 \mathrm{mmHg}$ (approximately three-fold; $P=.055$ ) or cardiovascular disease (approximately twofold; $P=.074$ ). Further controlling for total fruit and vegetable intake (Model 2) strengthened the associations between $\mathrm{BMI} \geq 25$ and diabetes and systolic blood pressure $>140 \mathrm{mmHg}$, and resulted in a significant association between BMI $\geq 25$ and diastolic blood pressure $\geq 90 \mathrm{mmHg}$. There were no associations between $\mathrm{BMI} \leq 20$ or $\mathrm{BMI} \geq 25$ and stroke, depression, or cancer in any of the regression models.

\section{Discussion}

To our knowledge, this is the first study to explore associations between dietary patterns and body weight status in the oldest old segment of the population. Prevalence of overweight/obesity in this population-based study of 
TABle 2: Demographics, dietary patterns, and health conditions of centenarians of varying BMI classification: The Georgia Centenarian Study.

\begin{tabular}{|c|c|c|c|c|}
\hline & $\begin{array}{c}\mathrm{BMI} \leq 20^{1} \\
\text { Median, range, } \\
\text { mean } \pm \mathrm{SD} \text {, or } \%\end{array}$ & $\begin{array}{c}\text { BMI }>20 \text { and }<25^{1} \\
\text { Median, range, } \\
\text { mean } \pm \text { SD, or } \%\end{array}$ & $\begin{array}{c}\text { BMI } \geq 25^{1} \\
\text { Median, range, } \\
\text { mean } \pm \mathrm{SD} \text {, or } \%\end{array}$ & $P$ \\
\hline Age & $\begin{array}{c}100.5,98.1-106.0 \\
100.8 \pm 1.8\end{array}$ & $\begin{array}{c}100.2,98.1-105.2 \\
100.5 \pm 1.8\end{array}$ & $\begin{array}{c}99.6,98.1-108.5 \\
100.2 \pm 2.1\end{array}$ & .051 \\
\hline \multicolumn{5}{|l|}{ Gender $^{2}$} \\
\hline Women & $34.5(68)$ & $41.1(81)$ & $24.4(48)$ & .042 \\
\hline Men & $13.9(5)$ & $58.3(21)$ & $27.8(10)$ & \\
\hline \multicolumn{5}{|l|}{ Race $^{2}$} \\
\hline White & $33.2(61)$ & $46.2(85)$ & $20.6(38)$ & .015 \\
\hline African American & $24.5(12)$ & $34.7(17)$ & $40.8(20)$ & \\
\hline \multicolumn{5}{|l|}{ Living arrangements ${ }^{2}$} \\
\hline Skilled nursing facility & $43.6(44)$ & $35.6(36)$ & $20.8(21)$ & .002 \\
\hline Community & $22.0(29)$ & $50.0(66)$ & $28.0(37)$ & \\
\hline \multicolumn{5}{|l|}{ B-vitamin supplements ${ }^{3}$} \\
\hline No & $61.6(45)$ & $63.7(65)$ & $74.1(43)$ & .281 \\
\hline Yes & $38.4(28)$ & $36.3(37)$ & $25.9(15)$ & \\
\hline \multirow{2}{*}{ Total food score ${ }^{4}$} & $4.0,0-5$ & $3.0,0-5$ & $2.0,0-5$ & \\
\hline & $3.5 \pm 1.6^{\mathrm{a}}$ & $3.0 \pm 1.5^{\mathrm{ab}}$ & $2.8 \pm 1.6^{\mathrm{b}}$ & .046 \\
\hline$<3$ & $37.0(27)$ & $49.0(50)$ & $55.2(32)$ & .097 \\
\hline$\geq 3$ & $63.0(46)$ & $51.0(52)$ & $44.8(26)$ & \\
\hline \multicolumn{5}{|l|}{$\begin{array}{l}\text { Meat, fish, poultry intake } \\
\text { (servings/day) }\end{array}$} \\
\hline$<2$ & $41.1(30)$ & $57.8(59)$ & $60.3(35)$ & .041 \\
\hline$\geq 2$ & $58.9(43)$ & $42.2(43)$ & $39.6(23)$ & \\
\hline \multicolumn{5}{|c|}{$\begin{array}{l}\text { Milk and dairy product intake } \\
\text { (servings/day) }\end{array}$} \\
\hline$<2$ & $45.2(33)$ & $55.9(57)$ & $59.6(34)$ & .210 \\
\hline$\geq 2$ & $54.8(40)$ & $44.1(45)$ & $40.4(23)$ & \\
\hline \multicolumn{5}{|l|}{$\begin{array}{l}\text { Green vegetable intake } \\
\text { (servings/week) }\end{array}$} \\
\hline$<4$ & $6.8(5)$ & $4.9(5)$ & $8.6(5)$ & .644 \\
\hline$\geq 4$ & $93.2(68)$ & $95.1(97)$ & $91.4(53)$ & \\
\hline \multicolumn{5}{|c|}{$\begin{array}{l}\text { Orange and yellow vegetable intake } \\
\text { (servings/week) }\end{array}$} \\
\hline$<3$ & $9.6(7)$ & $11.8(12)$ & $20.7(12)$ & .148 \\
\hline$\geq 3$ & $90.4(66)$ & $88.2(90)$ & $79.3(46)$ & \\
\hline \multicolumn{5}{|l|}{ Total fruit (servings/day) } \\
\hline$<3$ & $50.7(37)$ & $66.7(68)$ & $70.7(41)$ & .034 \\
\hline$\geq 3$ & $49.3(36)$ & $33.3(34)$ & $29.3(17)$ & \\
\hline \multicolumn{5}{|c|}{ Citrus fruit intake (servings/dly) } \\
\hline$<1$ & $27.4(20)$ & $34.3(35)$ & $50.0(29)$ & .025 \\
\hline$\geq 1$ & $72.6(53)$ & $65.7(67)$ & $50.0(29)$ & \\
\hline \multicolumn{5}{|l|}{$\begin{array}{l}\text { Noncitrus fruit intake } \\
\text { (servings/day) }\end{array}$} \\
\hline$<1$ & $24.7(18)$ & $34.3(35)$ & $46.6(27)$ & .032 \\
\hline$\geq 1$ & $75.3(55)$ & $65.7(67)$ & $53.4(31)$ & \\
\hline
\end{tabular}


Table 2: Continued.

\begin{tabular}{|c|c|c|c|c|}
\hline & $\begin{array}{c}\mathrm{BMI} \leq 20^{1} \\
\text { Median, range, } \\
\text { mean } \pm \mathrm{SD} \text {, or } \%\end{array}$ & $\begin{array}{c}\text { BMI }>20 \text { and }<25^{1} \\
\text { Median, range, } \\
\text { mean } \pm \mathrm{SD} \text {, or } \%\end{array}$ & $\begin{array}{c}\text { BMI } \geq 25^{1} \\
\text { Median, range, } \\
\text { mean } \pm \mathrm{SD} \text {, or } \%\end{array}$ & $P$ \\
\hline \multicolumn{5}{|c|}{$\begin{array}{l}\text { Orange and yellow vegetable intake } \\
\text { (servings/week) }\end{array}$} \\
\hline$<4$ & $23.3(17)$ & $24.5(25)$ & $41.4(24)$ & .038 \\
\hline$\geq 4$ & $76.7(56)$ & $75.5(77)$ & $58.6(34)$ & \\
\hline \multicolumn{5}{|l|}{$\begin{array}{l}\text { Total fruit and vegetables } \\
\text { (servings/day) }\end{array}$} \\
\hline$<3$ & $17.8(13)$ & $25.5(26)$ & $37.9(22)$ & .033 \\
\hline$\geq 3$ & $82.2(60)$ & $74.5(76)$ & $62.1(36)$ & \\
\hline \multicolumn{5}{|l|}{ Needs help at mealtime } \\
\hline Yes & $42.5(31)$ & $29.4(30)$ & $24.1(14)$ & .060 \\
\hline No & $57.5(42)$ & $70.6(72)$ & $75.9(44)$ & \\
\hline \multicolumn{5}{|c|}{ Eats a typical diet of regular foods } \\
\hline Yes & $50.0(36)$ & $77.4(79)$ & $74.1(43)$ & .0003 \\
\hline No-foods modified & $50.0(36)$ & $22.6(23)$ & $25.9(15)$ & \\
\hline \multicolumn{5}{|c|}{$\begin{array}{l}\text { Body weight change in past } 3 \\
\text { months }\end{array}$} \\
\hline Loss & $28.2(20)$ & $20.6(20)$ & $12.3(7)$ & .040 \\
\hline Gain & $15.5(11)$ & $7.2(7)$ & $19.3(11)$ & \\
\hline No & $56.3(40)$ & $72.2(70)$ & $68.4(39)$ & \\
\hline \multicolumn{5}{|c|}{ Appetite loss in past 3 months } \\
\hline Yes (moderate/severe) & $11.3(8)$ & $13.9(14)$ & $5.3(3)$ & .249 \\
\hline No loss & $88.7(63)$ & $86.1(87)$ & $94.7(54)$ & \\
\hline Systolic BP, mmHg & $\begin{array}{c}122,90-160 \\
124.4 \pm 14.5^{\mathrm{a}}\end{array}$ & $\begin{array}{l}125,100-165 \\
126.2 \pm 12.7^{\mathrm{a}}\end{array}$ & $\begin{array}{l}130,110-190 \\
134.4 \pm 17.6^{b}\end{array}$ & .0013 \\
\hline$<140$ & $86.3(63)$ & $81.4(83)$ & $67.2(39)$ & .022 \\
\hline$\geq 140$ & $13.7(10)$ & $18.6(19)$ & $32.8(19)$ & \\
\hline Diastolic BP, mmHg & $\begin{array}{l}72,56-100 \\
73.0 \pm 8.5\end{array}$ & $\begin{array}{l}73,46-100 \\
73.2 \pm 8.8\end{array}$ & $\begin{array}{l}75,38-100 \\
76.0 \pm 11.1\end{array}$ & .261 \\
\hline$<90$ & $95.9(70)$ & $96.1(98)$ & $86.2(51)$ & .031 \\
\hline$\geq 90$ & $4.1(3)$ & $3.9(4)$ & $13.8(8)$ & \\
\hline \multicolumn{5}{|l|}{ Diabetes $^{5}$} \\
\hline Yes & $8.2(6)$ & $3.9(4)$ & $15.5(9)$ & .036 \\
\hline No & $91.8(67)$ & $96.1(98)$ & $84.5(49)$ & \\
\hline \multicolumn{5}{|l|}{ Anemia $^{6}$} \\
\hline Yes & $63.2(43)$ & $44.4(44)$ & $47.4(27)$ & .048 \\
\hline No & $36.8(25)$ & $55.6(55)$ & $52.6(30)$ & \\
\hline \multicolumn{5}{|l|}{$\mathrm{CVD}^{5}$} \\
\hline Yes & $58.9(43)$ & $61.8(63)$ & $69.0(40)$ & .482 \\
\hline No & $41.1(30)$ & $38.2(39)$ & $31.0(18)$ & \\
\hline \multicolumn{5}{|l|}{ Cancers $^{5}$} \\
\hline Yes & $31.5(23)$ & $31.4(32)$ & $24.1(14)$ & .574 \\
\hline No & $68.5(50)$ & $68.6(70)$ & $75.9(44)$ & \\
\hline \multicolumn{5}{|l|}{ Stroke ${ }^{5}$} \\
\hline Yes & $23.3(17)$ & $21.6(22)$ & $22.4(13)$ & .964 \\
\hline
\end{tabular}


TABle 2: Continued.

\begin{tabular}{|c|c|c|c|c|}
\hline & $\begin{array}{c}\mathrm{BMI} \leq 20^{1} \\
\text { Median, range, } \\
\text { mean } \pm \mathrm{SD} \text {, or } \%\end{array}$ & $\begin{array}{c}\text { BMI }>20 \text { and }<25^{1} \\
\text { Median, range, } \\
\text { mean } \pm \text { SD, or } \%\end{array}$ & $\begin{array}{c}\mathrm{BMI} \geq 25^{1} \\
\text { Median, range, } \\
\text { mean } \pm \mathrm{SD} \text {, or } \%\end{array}$ & $P$ \\
\hline No & $76.7(56)$ & $78.4(80)$ & $77.6(45)$ & \\
\hline \multicolumn{5}{|c|}{ Depression $^{5}$} \\
\hline Yes & $20.6(15)$ & $11.8(12)$ & $10.3(6)$ & \multirow[t]{2}{*}{.163} \\
\hline No & $79.4(58)$ & $88.2(90)$ & $89.7(52)$ & \\
\hline \multicolumn{5}{|c|}{ Current or past tobacco use ${ }^{5}$} \\
\hline Yes & $25.0(18)$ & $31.4(32)$ & $28.1(16)$ & \multirow[t]{2}{*}{.654} \\
\hline No & $75.0(54)$ & $68.6(70)$ & $71.9(41)$ & \\
\hline \multicolumn{5}{|c|}{ Current tobacco use $\mathrm{e}^{5}$} \\
\hline Yes & $1.4(1)$ & $3.9(4)$ & $3.5(2)$ & \multirow[t]{2}{*}{.612} \\
\hline No & $98.6(71)$ & $96.1(98)$ & $96.5(55)$ & \\
\hline \multicolumn{5}{|c|}{$\begin{array}{l}\text { a,b Means with different superscripts are significantly different, } P<.05 \text {. } \\
{ }_{n}^{1} n=73 \text { for BMI } \leq 20 ; n=102 \text { for BMI }>20 \text { and }<25 ; n=58 \text { for } \mathrm{BMI} \geq 25 \text {. } \\
2 \text { Percentages add up to } 100 \% \text { across a row. Number of participants represented by each percentage is included in brackets (). } \\
{ }^{3} \mathrm{~B} \text { vitamin supplements included multivitamin/mineral, B vitamins, or single oral supplements of vitamin B12. } \\
{ }^{4} \text { Total food score ranged from } 0 \text { to } 5 \text { and one point was given for meeting each recommended serving from five food groups as follows: two or more servings } \\
\text { of meat, poultry, or fish daily, two or more servings of dairy foods daily, four or more servings of green vegetables weekly, three or more servings of orange or } \\
\text { yellow vegetables weekly, and three or more servings of fruit daily (16). } \\
{ }^{5} \text { Information obtained from participant or a proxy by self-report. } \\
{ }^{6} \text { Based on laboratory values and defined as hemoglobin }<12 \mathrm{~g} / \mathrm{dL} \text { for females or }<13 \mathrm{~g} / \mathrm{dL} \text { for males }(20) \text {. }\end{array}$} \\
\hline
\end{tabular}

TABLE 3: Associations of dietary intake patterns with underweight or overweight/obesity in Georgia centenarians.

\begin{tabular}{|c|c|c|c|c|}
\hline \multirow[b]{2}{*}{ Independent Variable } & \multicolumn{2}{|c|}{$\mathrm{BMI} \leq 20^{\mathrm{a}}$} & \multicolumn{2}{|c|}{$\mathrm{BMI} \geq 25^{\mathrm{b}}$} \\
\hline & Odds ratio $(95 \% \mathrm{CI})$ & $P$ & Odds ratio $(95 \% \mathrm{CI})$ & $P$ \\
\hline Meat, $<2$ servings/day & $0.83(0.40-1.70)$ & .608 & $1.17(0.54-2.53)$ & .685 \\
\hline Dairy, $<2$ serving/day & $0.93(0.48-1.78)$ & .819 & $1.18(0.57-2.42)$ & .660 \\
\hline Fruit \& vegetables, $<3$ servings/day & $0.75(0.35-1.59)$ & .450 & $2.12(1.04-4.32)$ & .039 \\
\hline Orange/yellow vegetables, $<4$ servings/week & $1.17(0.56-2.44)$ & .684 & $2.27(1.11-4.65)$ & .025 \\
\hline Citrus fruit, $<1$ serving/day & $0.77(0.40-1.50)$ & .445 & $2.40(1.20-4.76)$ & .013 \\
\hline Noncitrus fruit, $<1$ serving/day & $0.73(0.36-1.45)$ & .362 & $2.18(1.09-4.38)$ & .028 \\
\hline
\end{tabular}

${ }^{\mathrm{a}}$ Determined by a series of logistic regression analyses with BMI $\leq 20$ versus BMI $\geq 20$ as the dependent variable, controlled for gender, race, and residence.

${ }^{b}$ Determined by a series of logistic regression analyses with BMI $\geq 25$ versus BMI $<25$ as the dependent variable, controlled for gender, race, and residence.

centenarians was approximately $25 \%$, which was considerably below the prevalence for these conditions in the overall population of older adults, aged 60 and above, in the USA at the time of data collection ( $69 \%$; [22]). In analyses controlled for gender, race, and place of residence, several parameters indicative of a low frequency of fruit and vegetable intake were associated with overweight/obesity (BMI $\geq 25)$, whereas there were no associations between frequency of intake of meat, dairy, and fruits and vegetables and being underweight $(\mathrm{BMI} \leq 20)$. Other findings include strong associations of underweight with anemia and of overweight/obesity with diabetes and high blood pressure, extending knowledge of such associations to the very old.

The present research was part of a large, multidisciplinary study across a range of cognitive, mental, physical, and health-associated domains exploring the role of various factors pertinent to the survival and functioning of centenarians. To decrease testing burden for participants, dietary intake data focused on frequency of intake of specific food groups selected based on the Dietary Guidelines for Americans and age-related associations with nutritional deficiencies and chronic diseases [16, 17]. Notably, we observed that based on frequency of intake and regardless of BMI classification, a large percentage of centenarians were not meeting the dietary guidelines for many food groups, with the exception of green and orange/yellow vegetables. This later finding is consistent with an apparent preference for sweet potatoes and green vegetables reported for an earlier convenience sampling of Georgia centenarians [23, 24]. Such preferences likely are reflective of the traditional diet of the Southeastern USA, rather than longevity-related differences in dietary patterns, and may not be replicable in other regions and cultures.

Our initial analysis indicated a greater intake of meat and total fruits in the underweight centenarians, suggesting that they were eating better than those in the normal weight and 
TABLE 4: Associations of underweight or overweight/obesity with health conditions or indicators in Georgia centenarians.

\begin{tabular}{|c|c|c|c|c|}
\hline \multirow[b]{2}{*}{ Dependent variable } & \multicolumn{2}{|c|}{$\mathrm{BMI} \leq 20^{\mathrm{a}}$} & \multicolumn{2}{|c|}{$\mathrm{BMI} \geq 25^{\mathrm{b}}$} \\
\hline & Odds ratio $(95 \% \mathrm{CI})$ & $P$ & Odds ratio $(95 \% \mathrm{CI})$ & $P$ \\
\hline \multicolumn{5}{|l|}{$\overline{\text { Diabetes }}$} \\
\hline Model 1 & $0.91(0.30-2.69)$ & .858 & $2.86(1.02-7.99)$ & .045 \\
\hline Model 2 & $0.89(0.30-2.64)$ & .837 & $3.11(1.11-8.75)$ & .031 \\
\hline \multicolumn{5}{|l|}{ Anemia } \\
\hline Model 1 & $2.47(1.32-4.62)$ & .004 & $0.72(0.38-1.36)$ & .309 \\
\hline Model 2 & $2.47(1.32-4.62)$ & .005 & $0.72(0.38-1.37)$ & .318 \\
\hline \multicolumn{5}{|c|}{ Systolic BP $\geq 140 \mathrm{mmHg}$} \\
\hline Model 1 & $0.72(0.32-1.61)$ & .425 & $2.09(1.02-4.27)$ & .043 \\
\hline Model 2 & $0.70(0.31-1.57)$ & .385 & $2.26(1.09-4.69)$ & .029 \\
\hline \multicolumn{5}{|c|}{ Diastolic BP $\geq 90 \mathrm{mmHg}$} \\
\hline Model 1 & $0.81(0.25-3.18)$ & .760 & $2.96(0.98-9.01)$ & .055 \\
\hline Model 2 & $0.71(0.18-2.79)$ & .621 & $3.81(1.21-12.05)$ & .022 \\
\hline \multicolumn{5}{|l|}{ CVD } \\
\hline Model 1 & $0.54(0.29-1.01)$ & .053 & $1.85(0.94-3.64)$ & .074 \\
\hline Model 2 & $0.53(0.28-1.00)$ & .048 & $1.95(0.98-3.88)$ & .058 \\
\hline \multicolumn{5}{|l|}{ History of cancer } \\
\hline Model 1 & $1.09(0.58-2.07)$ & .791 & $0.82(0.40-1.66)$ & .575 \\
\hline Model 2 & $1.08(0.57-2.05)$ & .818 & $0.87(0.42-1.77)$ & .694 \\
\hline \multicolumn{5}{|l|}{ Stroke } \\
\hline Model 1 & $0.91(0.46-1.82)$ & .791 & $1.18(0.57-2.47)$ & .655 \\
\hline Model 2 & $0.91(0.46-1.83)$ & .794 & $1.18(0.56-2.47)$ & .667 \\
\hline \multicolumn{5}{|l|}{ Depression } \\
\hline Model 1 & $1.12(0.49-2.57)$ & .782 & $0.89(0.32-2.50)$ & .829 \\
\hline Model 2 & $1.22(0.53-2.80)$ & .640 & $0.91(0.32-2.58)$ & .854 \\
\hline
\end{tabular}

${ }^{\mathrm{a}}$ Determined by a series of logistic regression analyses with BMI $\leq 20$ versus BMI $>20$ as an independent variable, controlled for gender, race, and residence (Model 1) or for gender, race, residence, and total fruit and vegetable intake ( $<3$ servings/day $=1 ;>3$ servings/day $=0)($ Model 2).

${ }^{b}$ Determined by a series of logistic regression analyses with BMI $\geq 25$ versus BMI $<25$ as an independent variable, controlled for gender, race, and residence (Model 1) or for gender, race, residence, and total fruit and vegetable intake $(<3$ servings/day $=1 ;>3$ servings/day $=0)($ Model 2$)$.

overweight/obese classifications. The underweight centenarians also had the highest total food scores, suggesting that they were meeting more of the recommended servings for specific food groups [17]. However, almost twice as many underweight centenarians lived in skilled nursing facilities as compared to the community, and there was no association between low BMI and dietary groups after controlling for race, residence, and gender. In a specific comparison between centenarians residing in skilled nursing facilities and in the community, Johnson et al. [16] reported that those in skilled nursing facilities were more likely to eat three or more meals a day and to have a higher frequency of intake of most food groups. They suggested that such differences may be due to (1) the requirement that skilled nursing facilities serve meals that meet dietary guidelines and other federal nutrition policies $[25,26],(2)$ the inability of the methodology used to distinguish between food that was served and food that was eaten, and (3) barriers faced by community dwelling centenarians or their caregivers in purchasing, preparing, or consuming appropriate food to meet their nutritional needs. Thus, associations in centenarians between low BMI and dietary status may be quite complex and influenced considerably by place of residence.
In the present study, there was an increase in the relative risk for being overweight/obese in centenarians reporting the lowest frequency of intake of some nutrient dense foods including orange/yellow vegetables and citrus and noncitrus fruits. These observations are consistent with previous studies finding associations between lower reported or inferred consumption of fruits and/or vegetables and increased prevalence of overweight/obesity in children [27] and young to middle-age adults [5, 28-30]. Interestingly, other studies in adults have indicated that increased consumption of fruits and vegetables may be an effective strategy for decreasing energy consumption and for increasing and maintaining weight loss $[29,31,32]$. In addition to potential beneficial effects on body weight, there is considerable evidence in other age groups that high consumption of fruits and vegetables may offer protective effects against and/or to reduce the relative risk of cardiovascular disease, hypertension, diabetes, and certain cancers [33-40]. We observed that centenarians in the highest weight category (BMI $\geq 25)$ reported eating lower amounts of certain types of fruits and vegetables than their nonoverweight/nonobese counterparts and also appeared to be at greater risk for diabetes, high blood pressure, and cardiovascular disease. 
This suggests that a high intake of fruits and vegetables may be beneficial for maintaining optimal weight, and perhaps decreasing risk of chronic disease, even at very advanced age. However, additional, ideally longitudinal, research collecting more detailed food intake data is needed to support this contention. In addition, as social isolation, missing teeth, digestion difficulties, poor self-reported health, cost and preparation issues have been identified as barriers to fruit and vegetable intake in older adults [41-43], research is needed to determine if and to what degree these or other potential barriers may be influencing the intake of fruit, vegetables, and other low energy, high nutrient dense foods in the very old.

Clinically defined anemia was present in greater than $60 \%$ of the centenarians in the lowest BMI grouping. After controlling for demographic covariates, a strong association remained between low BMI and anemia but not with other health conditions and indicators. Accordingly, low BMI had been identified as an independent correlate or risk factor for anemia in some previous studies in older adults and clinical populations [44-46], but not in others [47]. Although older adults with a low BMI are considered to be at nutritional risk $[47,48]$, it cannot be assumed that the anemia observed in underweight older adults is primarily of dietary or nutritional etiology. Indeed, our previous studies indicate a similar prevalence of anemia in vitamin B12deficient and vitamin B12-adequate in Georgia centenarians [7] and a high prevalence of inflammatory anemia, either alone or in combination with nutritional deficiencies, in this population [49]. Nonetheless, as anemia is associated with increased mortality in acute and chronic disease states, particularly in those underweight $[50,51]$, it is important to monitor and treat this condition, as appropriate, in the very old.

In summary, this secondary analysis provides evidence of an inverse association between fruit and vegetable intake and body weight status in a population-based study of centenarians. In addition, both underweight and overweight emerged as potential risk factors for various chronic diseases, emphasizing the importance of monitoring weight and of maintaining a healthy weight, even at very advanced ages. A major strength of the study is the inclusion of a populationbased sampling of centenarians with greater diversity in race, place of residence, and functional status than would be typically obtained with a convenience sample. Limitations of the study include the relatively small sample size, lack of information regarding physical activity, and reliance on data of frequency of intake for only a few food groupings rather than the use of a more extensive food frequency questionnaire including individual foods and serving sizes as per our earlier convenience study of centenarians [23, 24]. Absence of intake data on key dietary components including grains/cereals and sweets/desserts necessitated the use a series of nonindependent binary logistic regression models instead of a more complex, single multinomial logistic regression to explore potential associations between BMI and dietary intake patterns. Thus, specifically designed studies including more detailed information of dietary intake, physical activity data, and additional chronic disease indicators are needed to verify associations, or lack thereof, between dietary intake patterns, weight status, and chronic health conditions in the very old. Furthermore, as dietary habits and other characteristics of this sample from Georgia likely differ from those of centenarians from other countries and cultures, our findings need replication in other population groups.

\section{Acknowledgments}

Authors acknowledge the valuable recruitment and data acquisition effort from M. Burgess, K. Grier, E. McCarthy, L. Strong, and S. Reynolds, data acquisition team manager; S. Anderson, M. Janke, and T. Savla, data management; M. Poon for project fiscal management. A preliminary report of these data was presented at the Experimental Biology 2011 meeting, Washington, DC. The Georgia Centenarian Study (Leonard W. Poon, PI) is funded by 1P01-AG17553 from the National Institute on Aging. Additional investigators in the Georgia Centenarian Study include Jonathan Arnold (University of Georgia), Marla Gearing (Emory University School of Medicine), Robert C. Green (Boston University School of Medicine), S. Michal Jazwinski (Tulane University Health Sciences Center), Peter Martin (Iowa State University), Maurice MacDonald (Iowa State University), William R. Markesbery (deceased), Willard L. Rodgers (University of Michigan), John L. Woodard (Wayne State University), Christopher Rott (University of Heidelberg), Ilene C. Siegler (Duke University), and J. Lisa Tenover (Palo Alto VA Health Care System).

\section{References}

[1] K. C. Neidert and B. Borner, Nutrition Care of the Older Adult: A Handbook for Dietetics Professionals Working throughout the Continum of Care, American Dietetic Association, 2nd edition.

[2] K. Kitamura, K. Nakamura, T. Nishiwaki, K. Ueno, and M. Hasegawa, "Low body mass index and low serum albumin are predictive factors for short-term mortality in elderly Japanese requiring home care," Tohoku Journal of Experimental Medicine, vol. 221, no. 1, pp. 29-34, 2010.

[3] D. T. Villareal, C. M. Apovian, R. F. Kushner, and S. Klein, "Obesity in older adults: technical review and position statement of the American Society for Nutrition and NAASO, The Obesity Society," American Journal of Clinical Nutrition, vol. 82, no. 5, pp. 923-934, 2005.

[4] D. K. Houston, B. J. Nicklas, and C. A. Zizza, "Weighty concerns: the growing prevalence of obesity among older adults," Journal of the American Dietetic Association, vol. 109, no. 11, pp. 1886-1895, 2009.

[5] M. Tjepkema, "Adult obesity," Health Reports/Statistics Canada, vol. 17, no. 3, pp. 9-25, 2006.

[6] M. A. Johnson, A. Davey, S. Park, D. B. Hausman, and L. W. Poon, "Age, race and season predict vitamin D status in African American and White centenarians and octogenarians," Journal of Nutrition, Health and Aging, vol. 12, pp. 690-695, 2008.

[7] M. A. Johnson, D. B. Hausman, A. Davey, L. W. Poon, R. H. Allen, and S. P. Stabler, "Vitamin B12 deficiency in African American and white octogenarians and centenarians in Georgia," Journal of Nutrition, Health and Aging, vol. 14, no. 5, pp. 339-345, 2010. 
[8] A. M. Paradis, G. Godin, L. Pérusse, and M. C. Vohl, "Associations between dietary patterns and obesity phenotypes," International Journal of Obesity, vol. 33, no. 12, pp. 1419-1426, 2009.

[9] J. H. Ledikwe, H. Smiciklas-Wright, D. C. Mitchell, C. K. Miller, and G. L. Jensen, "Dietary patterns of rural older adults are associated with weight and nutritional status," Journal of the American Geriatrics Society, vol. 52, no. 4, pp. 589-595, 2004.

[10] P. K. Newby, D. Muller, J. Hallfrisch, R. Andres, and K. L. Tucker, "Food patterns measured by factor analysis and anthropometric changes in adults," The American Journal of Clinical Nutrition, vol. 80, no. 2, pp. 504-513, 2004.

[11] A. L. Anderson, T. B. Harris, F. A. Tylavsky et al., "Dietary patterns and survival in older adults," Journal of the American Dietetic Association, vol. 111, pp. 84-91, 2011.

[12] D. B. Hausman, J. G. Fischer, and M. A. Johnson, "Nutrition in centenarians," Maturitas, vol. 68, pp. 203-209, 2011.

[13] A. Davey, M. F. Elias, I. C. Siegler et al., "Cognitive function, physical performance, health, and disease: norms from the Georgia centenarian study," Experimental Aging Research, vol. 36, pp. 394-425, 2010.

[14] L. W. Poon, S. M. Jazwinski, R. C. Green et al., "Methodological considerations in studying centenarians: lessons learned from the Georgia centenarian studies," Annual Review of Gerontology and Geriatrics, vol. 27, pp. 213-264, 2007.

[15] Y. Guigoz, B. Vellas, and P. J. Garry, "Assessing the nutritional status of the elderly: the Mini Nutritional Assessment as part of the geriatric evaluation," Nutrition Reviews, vol. 54, no. 1, pp. S59-S65, 1996.

[16] M. A. Johnson, A. Davey, D. B. Hausman et al., "Dietary differences between centenarians residing in communities and in skilled nursing facilities: the Georgia Centenarian Study," Age, vol. 28, no. 4, pp. 333-341, 2006.

[17] US Department of Health and Human Services and US Department of Agriculture, "Dietary Guidelines for Americans 2005,” 2005, http://www.health.gov/dietaryguidelines/ dga2005/document/pdf/DGA2005.pdf.

[18] W. C. Chumlea, S. S. Guo, K. Wholihan, D. Cockram, R. J. Kuczmarski, and C. L. Johnson, "Stature prediction equations for elderly non-Hispanic white, non-Hispanic black, and Mexico-American persons developed from NHANES III data," Journal of the American Dietetic Association, vol. 98, no. 2, pp. 137-142, 1998.

[19] National Institutes of Health: National Heart Lung and Blood Institute, North American Association for the Study of Obesity, "Practical Guide to the Identification, Evaluation, and Treatment of Overweight and Obesity in Adults," 2000, http://www.nhlbi.nih.gov/guidelines/obesity/prctgd_c.pdf.

[20] B. Blanc, C. A. Finch, L. Hallberg et al., "Nutritional anaemias. Report of a WHO Scientific Group," WHO Technical Report Series, no. 40, pp. 1-40, 1968.

[21] M. A. McDowell, C. D. Fryar, C. L. Ogden, and K. M. Flegal, "Anthropometric reference data for children and adults: United States, 2003-2006," National Health Statistics Reports, Number 10, October 2008, http://www.cdc.gov/nchs/data/ nhsr/nhsr010.pdf.

[22] C. L. Ogden, M. D. Carroll, L. R. Curtin, M. A. McDowell, C. J. Tabak, and K. M. Flegal, "Prevalence of overweight and obesity in the United States, 1999-2004," Journal of the American Medical Association, vol. 295, no. 13, pp. 1549-1555, 2006.

[23] M. A. Johnson, M. A. Brown, L. W. Poon, P. Martin, and G. M. Clayton, "Nutritional patterns of centenarians," International Journal of Aging and Human Development, vol. 34, no. 1, pp. 57-76, 1992.
[24] D. K. Houston, M. A. Johnson, L. W. Poon, and G. M. Clayton, "Individual foods and food group patterns of the oldest old," Journal of Nutrition for the Elderly, vol. 13, no. 4, pp. 5-23, 1994.

[25] V. H. Castellanos, "Food and nutrition in nursing homes," Generations, vol. 28, no. 3, pp. 65-71, 2004.

[26] N. S. Wellman and B. Kamp, "Federal food and nutrition assistance programs for older people," Generations, vol. 28, no. 3, pp. 78-85, 2004.

[27] J. Aranceta, C. Pérez-Rodrigo, L. Serra-Majem et al., "Prevention of overweight and obesity: a Spanish approach," Public Health Nutrition, vol. 10, no. 10A, pp. 1187-1193, 2007.

[28] L. Wang, J. M. Gaziano, E. P. Norkus, J. E. Buring, and H. D. Sesso, "Associations of plasma carotenoids with risk factors and biomarkers related to cardiovascular disease in middle-aged and older women," American Journal of Clinical Nutrition, vol. 88, no. 3, pp. 747-754, 2008.

[29] K. E. E. Schroder, "Effects of fruit consumption on body mass index and weight loss in a sample of overweight and obese dieters enrolled in a weight-loss intervention trial," Nutrition, vol. 26, no. 7-8, pp. 727-734, 2010.

[30] T. Andreyeva, M. W. Long, K. E. Henderson, and G. M. Grode, "Trying to lose weight: diet strategies among Americans with overweight or obesity in 1996 and 2003," Journal of the American Dietetic Association, vol. 110, no. 4, pp. 535-542, 2010.

[31] J. Kruger, H. M. Blanck, and C. Gillespie, "Dietary practices, dining out behavior, and physical activity correlates of weight loss maintenance," Preventing Chronic Disease, vol. 5, no. 1, p. A11, 2008.

[32] M. C. de Oliveira, R. Sichieri, and R. Venturim Mozzer, "A low-energy-dense diet adding fruit reduces weight and energy intake in women," Appetite, vol. 51, no. 2, pp. 291-295, 2008.

[33] S. Liu, J. E. Manson, I. M. Lee et al., "Fruit and vegetable intake and risk of cardiovascular disease: the Women's Health Study," American Journal of Clinical Nutrition, vol. 72, no. 4, pp. 922$928,2000$.

[34] K. J. Joshipura, F. B. Hu, J. E. Manson et al., "The effect of fruit and vegetable intake on risk for coronary heart disease," Annals of Internal Medicine, vol. 134, no. 12, pp. 1106-1114, 2001.

[35] L. A. Bazzano, J. He, L. G. Ogden et al., "Fruit and vegetable intake and risk of cardiovascular disease in US adults: the first National Health and Nutrition Examination Survey Epidemiologic Follow-up Study," American Journal of Clinical Nutrition, vol. 76, no. 1, pp. 93-99, 2002.

[36] E. Riboli and T. Norat, "Epidemiologic evidence of the protective effect of fruit and vegetables on cancer risk," American Journal of Clinical Nutrition, vol. 73, supplement 3, pp. 559S-569S, 2003.

[37] L. P. Svetkey, T. P. Erlinger, W. M. Vollmer et al., "Effect of lifestyle modifications on blood pressure by race, sex, hypertension status, and age," Journal of Human Hypertension, vol. 19, no. 1, pp. 21-31, 2005.

[38] F. J. van Duijnhoven, H. B. Bueno-de-Mesquita, P. Ferrari et al., "Fruit, vegetables, and colorectal cancer risk: the European Prospective Investigation into Cancer and Nutrition," American Journal of Clinical Nutrition, vol. 89, pp. 1441-1452, 2009.

[39] K. Esposito, C. M. Kastorini, D. B. Panagiotakos, and D. Giugliano, "Prevention of type 2 diabetes by dietary patterns: a systemic review of prospective studies and meta-analysis," Metabolic Syndrome and Related Disorders, vol. 8, pp. 471-476, 2010. 
[40] P. Carter, L. J. Gray, J. Troughton, K. Khunti, and M. J. Davies, "Fruit and vegetable intake and incidence of type 2 diabetes: systemic review and meta-analysis," British Medical Journal, vol. 341, p. c4229, 2010.

[41] G. Tsakos, K. Herrick, A. Sheiham, and R. G. Watt, "Edentulism and fruit and vegetable intake in low-income adults," Journal of Dental Research, vol. 89, no. 5, pp. 462-467, 2010.

[42] S. J. Hendrix, J. G. Fischer, S. Reddy et al., "Fruit and vegetable intake and knowledge increased following a community-based intervention in older adults in Georgia senior centers," Journal of Nutrition for the Elderly, vol. 27, no. 1-2, pp. 155-178, 2008.

[43] N. R. Sahyoun, X. L. Zhang, and M. K. Serdula, "Barriers to the consumption of fruits and vegetables among older adults," Journal of Nutrition for the Elderly, vol. 24, no. 4, pp. 5-21, 2006.

[44] C. W. Choi, J. Lee, K. H. Park et al., "Prevalence and characteristics of anemia in the elderly: cross-sectional study of three urban Korean population samples," American Journal of Hematology, vol. 77, no. 1, pp. 26-30, 2004.

[45] H. Ohwada, T. Nakayama, N. Nara, Y. Tomono, and K. Yamanaka, "An epidemiological study on anemia among institutionalized people with intellectual and/or motor disability with special reference to its frequency, severity and predictors," BMC Public Health, vol. 6, article 85, 2006.

[46] B. Dilorio, M. Cirillo, V. Bellizzi, D. Stellato, and N. G. DeSanto, "Prevalence and correlates of anemia and uncontrolled anemia in chronic hemodialysis patients-the Campania Dialysis Registry," International Journal of Artificial Organs, vol. 30, pp. 325-333, 2007.

[47] A. Ramel, P. V. Jonsson, S. Bjornsson, and I. Thorsdottir, "Anemia, nutritional status, and inflammation in hospitalized elderly," Nutrition, vol. 24, no. 11-12, pp. 1116-1122, 2008.

[48] L. Watson, W. Leslie, and C. Hankey, "Under-nutrition in old age: diagnosis and management," Reviews in Clinical Gerontology, vol. 16, no. 1, pp. 23-34, 2006.

[49] A. Haslam, Anemia in Georgia centenarians and octogenarians, M.S. thesis, University of Georgia, Athens, Ga, USA, 2010.

[50] R. D. Semba, M. O. Ricks, L. Ferrucci et al., "Types of anemia and mortality among older disabled women living in the community: the Women's Health and Aging Study I," Aging Clinical and Experimental Research, vol. 19, no. 4, pp. 259-264, 2007.

[51] D. Aronson, M. Nassar, T. Goldberg, M. Kapeliovich, H. Hammerman, and Z. S. Azzam, "The impact of body mass index on clinical outcomes after acute myocardial infarction," International Journal of Cardiology, vol. 145, pp. 476-480, 2010. 


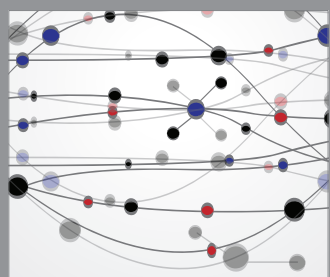

The Scientific World Journal
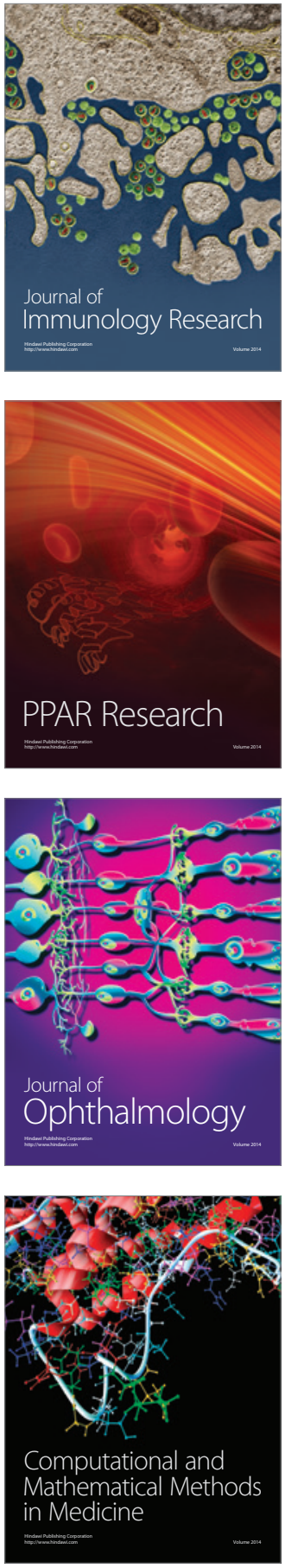

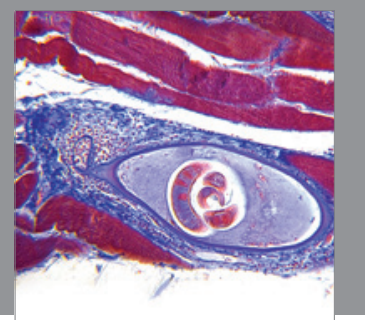

Gastroenterology

Research and Practice
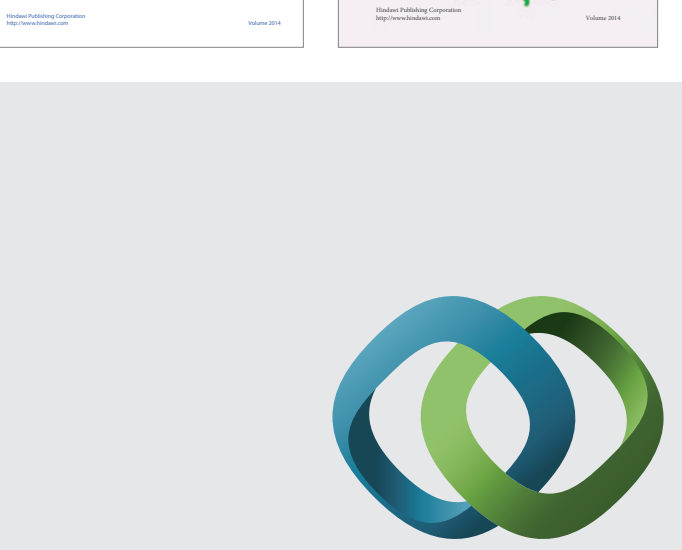

\section{Hindawi}

Submit your manuscripts at

http://www.hindawi.com
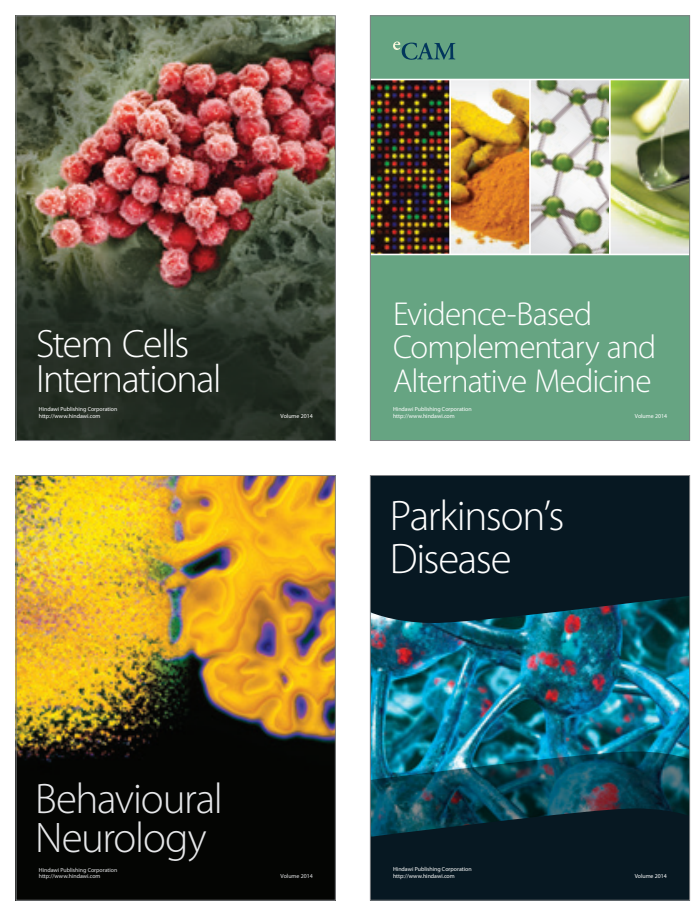

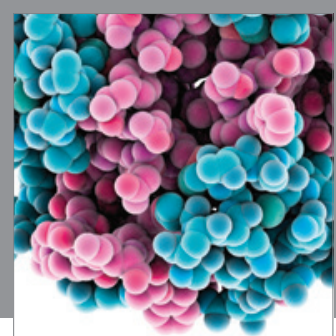

Journal of
Diabetes Research

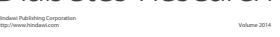

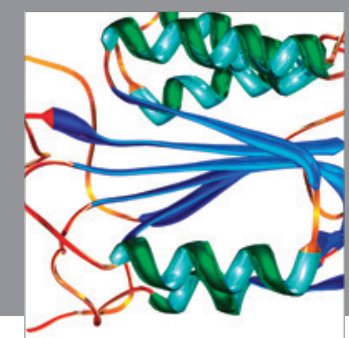

Disease Markers
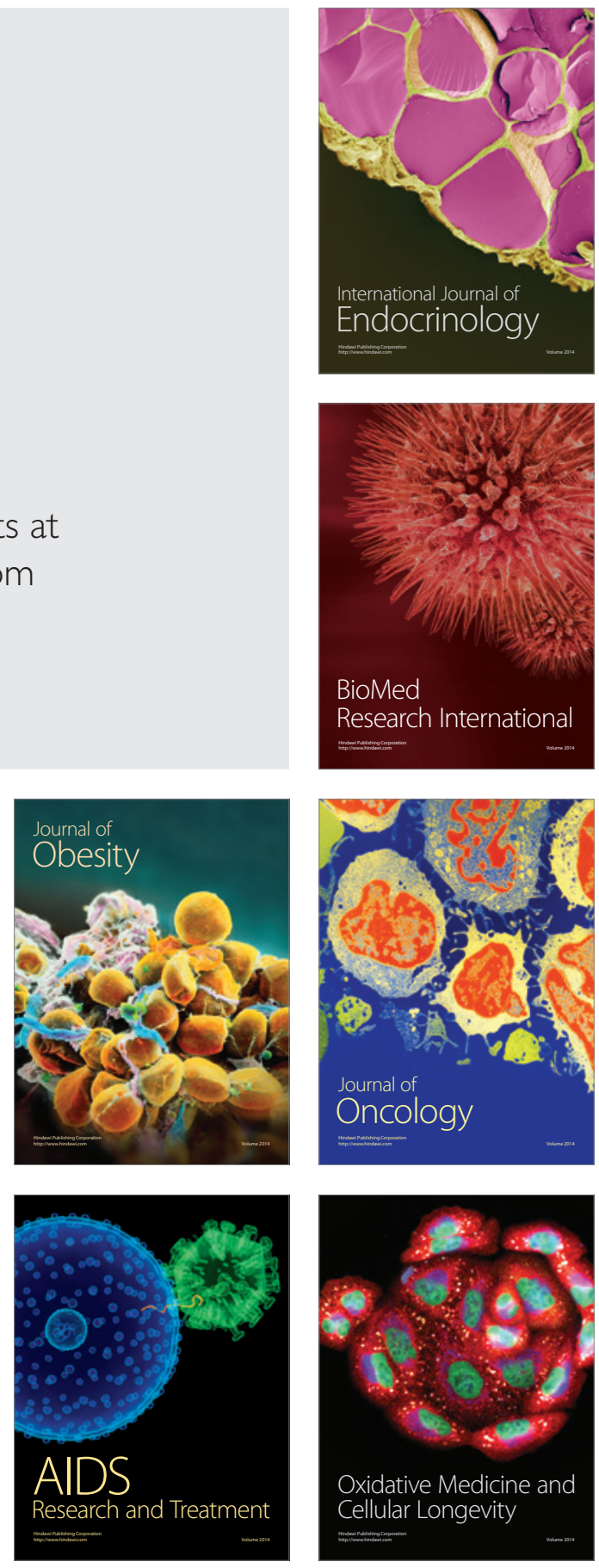